\title{
Knowledge management systems in Quality 4.0
}

\author{
Raluca Dovleac ${ }^{1, *}$ \\ ${ }^{1}$ Management and Industrial Engineering Department, University of Petroşani, Romania
}

\begin{abstract}
Quality management has evolved throughout time in ways that allowed companies to adapt quality practices and principles into their activities in order to provide better products/services to their customer. The latest trends point to the pivotal role that quality plays in the Industry 4.0 era, where it is expected to synergize with Industry 4.0 practices in order to ensure that not only products are built faster and cheaper but also that they can meet the quality expectations of the customers. This gave birth to the concept of Quality 4.0, a new way of managing quality which uses modern technologies such as: IoT, Blockchain, Big data, AI and sensors in order to gather relevant information, monitor process performance and act preemptively in regard to the quality of the process output. An issue that emerges however, is identifying the relevant data and ways to manage it as this is considered to be a major obstacle in the implementation of Quality 4.0 practices. The research focuses on providing the foundational base for Knowledge management practices of companies looking to embrace Quality 4.0 to ensure that these companies use relevant data in their daily activities.
\end{abstract}

\section{Introduction}

The technologies advances that society is witnessing have left a mark on businesses from all industries and sectors of activity. One of the most recent trends that highlighted the positive impact of technology in daily operations has been the emergence of Industry 4.0. Industry 4.0 focuses on directing the power of digitalization and digital technologies towards increasing the efficiency and competitivity of companies.

Closely related to the Industry 4.0 term, the field of quality management has registered a raising trend regarding the possibility of using modern technologies to help increase efficiency and product quality. Like so, the term "Quality 4.0" emerged, to help describe the relationship between quality management and Industry 4.0 practices.

Quality 4.0 highlights eight key components for effective implementation and focuses on using the tools and technologies available currently in order to help provide quality management solutions for companies that operate within Industry 4.0. In this context, it becomes important to understand what Quality 4.0 refers to and what are the requirements of Quality 4.0 as well as what are some of the observed requirements of companies within Industry 4.0.

\footnotetext{
* Corresponding author: raluca.dovleac@yahoo.com
} 
The paper focuses on a key aspect identified as an enabler of Quality 4.0 and which is going to play an essential role in the successful implementation of Quality 4.0 - knowledge management. Starting from the observations that highlight a need to focus on the type of data that Quality 4.0 requires and ways to manage this data, the author proposes a knowledge management model specific to Quality 4.0. The model is presented in section 4 "Results and conclusions" and has been designed by taking into account not only the Quality 4.0 tools available currently but also each stage of the knowledge management life cycle.

\section{Literature review}

Quality 4.0 evolved as a natural response to the changes in the manufacturing field, where in 2011, the term Industry 4.0 appeared to define a new way of increasing the competitiveness of the German manufacturing industry [1]. Industry 4.0 is based on digital transformation and has been used to describe the fourth industrial revolution [2].

In this context, Quality 4.0 aims to meet the requirements of Industry 4.0 companies by including digitalization of quality management systems [3] and practices as well as by adopting digital tools to increase efficiency and product quality [4] [5]. Furthermore, Quality 4.0 supports the digitalization of quality management including not only the products and the technologies but also the processes and the people [2] [1].

Although the literature in the field of Quality 4.0 is scarce, there are a couple of papers that cover the topic, from papers that focus on providing a literature review on the topic [1] [3], to papers that highlight the key points of implementing Quality 4.0 in an organization [4] [6], papers that focus on the role of Quality 4.0 in complex customer loyalty measurement [7], and papers that focus on the future of Quality 4.0 and the transition to Quality 5.0 [2].

As for the key components of Quality 4.0 and its effective implementation, a study by Sony et al [4] identified and described the following, presented in Figure 1.

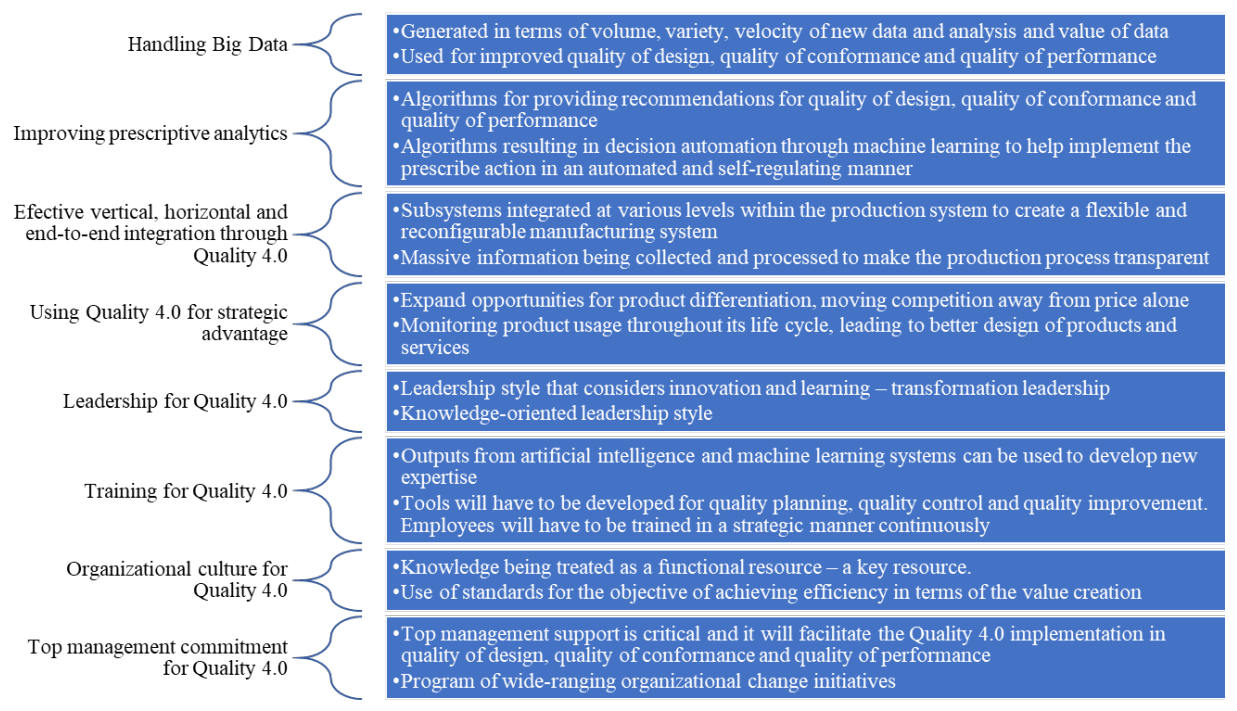

Fig. 1. Key ingredients of Quality 4.0 implementation [4]

As it can be observed from the figure, a major component of Quality 4.0 is the integration and usage of data and furthermore knowledge, in order to improve not only the 
quality of design, quality of conformance and quality of performance but also for optimizing activities taking place within a company and the production process. Another major aspect is the support of top management and the selection of current tools and training modules to be implemented in the case of companies looking to integrate Quality 4.0. It can also be observed that Knowledge Management will play a crucial role in Quality 4.0 implementation and effectiveness.

Knowledge management (KM) refers to the process or set of processes through which an organization makes use of the individual and collective intelligence within itself, in order to reach the established strategic goals [8]. Furthermore, it aims not only at creating and/or acquiring knowledge but also to the practices involved in storing, retaining, transferring and using the available knowledge [9] [10].

Regarding the possibility of implementing KM practices and tools within companies that have implemented Total Quality Management (TQM) practices, there are studies which highlight the complementarity of the two disciplines [11], and how they can integrate seamlessly to help the organizations become competitive and efficient [8], as well as studies analysing at the implications and possible benefits of integrating $\mathrm{KM}$ in various quality management practices [12] [13] [14].

\section{Research methodology}

\subsection{Research background}

The research is concerned with the role that KM will play in Quality 4.0 and the aspects that will emerge as a result. The aim of the paper therefore is to help clarify the aspects of $\mathrm{KM}$ that will remain unchanged in companies looking to implement Quality 4.0 as well as highlighting those areas that will require thorough consideration and possibly even some form of adaptation in order to fit the requirements of these companies.

In the context of Quality 4.0 becoming a trend for companies looking to benefit from the advantages that technology and Industry 4.0 brings along, the role of KM becomes clearer and the issue of collecting and managing efficiently data becomes more pressing. As debated by authors before, we are entering a phase in which "companies are data rich but information poor" [15]. It is therefore more important than ever to evaluate the role of information and the ways that it can be managed in order to ensure that companies integrating Quality 4.0 will be information rich.

\subsection{Methodology}

The literature review part of the paper has been completed by researching articles found from various sources and that were relevant. The selection process of the relevant articles consisted of a two-step process as presented in Figure 2, where selected research articles have been reviewed and then additional research articles recommended from the bibliography of the reviewed research articles have been analysed.

When searching for research articles, the author used a set of keywords, looking to also cover possible abbreviations for the relevant terms. The main keywords used were: "Knowledge management", "Knowledge management systems", "KM", "KMS", "Quality KM", "Quality KMS", "Quality knowledge management", "Quality knowledge management system", "Quality 4.0”, "Quality 4.0 KM", “Quality 4.0 KMS”, “Quality 4.0 knowledge management", "Quality 4.0 knowledge management system", "Quality Industry 4.0", "Quality 4.0 Industry 4.0", "Quality Big Data", "Quality 4.0 Big Data", "Quality IoT”, "Quality 4.0 IoT”, "Quality Blockchain”, "Quality 4.0 Blockchain". 
Furthermore, based on the results of the search, papers that didn't focus necessarily on Quality 4.0 and its implications but studied aspects related to the topic were taken into account, while papers that only presented keywords in the title or abstract of the paper but didn't cover the topic within the paper were dismissed.

\begin{tabular}{|c|c|}
\hline $\begin{array}{l}\text { Sources } \\
\text { Web of Science } \\
\text { Scopus } \\
\text { Google Scholar } \\
\text { Research Gate }\end{array}$ & $\begin{array}{l}\text { Search parameters } \\
\text { Year: 2010-2021 } \\
\text { Keywords: Knowledge management, } \\
\text { Knowledge management systems, KM, } \\
\text { KM systems, Quality 4.0, QMS 4.0, } \\
\text { Industry 4.0, KMS in Quality 4.0, } \\
\text { Quality 4.0 Big Data, Quality IoT. }\end{array}$ \\
\hline \multicolumn{2}{|c|}{$\downarrow$} \\
\hline \multicolumn{2}{|c|}{$\begin{array}{l}\text { Assessing papers relevancy } \\
\text { Inclusion criteria: } \\
\text { There must be a link between Quality and Industry } 4.0 \text { technologies } \\
\text { (IoT, Big Data, etc.) } \\
\text { Studies adressing state of the art Quality practices, Quality } 4.0 \\
\text { and Quality } 5.0 \text { elements and methodologies } \\
\text { Studies on Knowledge Management theories and practices in } \\
\text { the case of Quality and Quality } 4.0 \\
\text { Exclusion criteria: } \\
\text { Studies written in a language other than English } \\
\text { Studies published more than } 10 \text { years ago } \\
\text { Studies that didn't fully cover the topic presented in the abstract }\end{array}$} \\
\hline & $\nabla$ \\
\hline \multicolumn{2}{|c|}{$\begin{array}{l}\text { Review of literature } \\
\text { In depth review of the selected articles and highlighting the gist } \\
\text { ideas of the articles along with studying of the recommendations } \\
\text { and further research directions }\end{array}$} \\
\hline & $\nabla$ \\
\hline \multicolumn{2}{|c|}{$\begin{array}{l}\text { Identifying further research articles } \\
\text { From the bibliography and recommendation sections of the already } \\
\text { reviewed reseach articles }\end{array}$} \\
\hline
\end{tabular}

Fig. 2. Selection process for research articles review

A total number of 18 research articles were eventually consulted and reviewed for the literature review part of the paper and to help draw some conclusions that would prove to be the building blocks of the solution proposed in the paper.

\section{Results}

The analysis of the available literature highlighted the important role that KM plays within organizations in general and in the case of organizations that have already implemented or are looking to implement Quality 4.0.

An important aspect that the literature review revealed was related to the different types of knowledge that can exist within a company, with most companies being rich in tacit knowledge (estimated at $95 \%$ of all knowledge within the company) and very poor in explicit knowledge (estimated at 5\% within the company) as shown in Figure 3. 


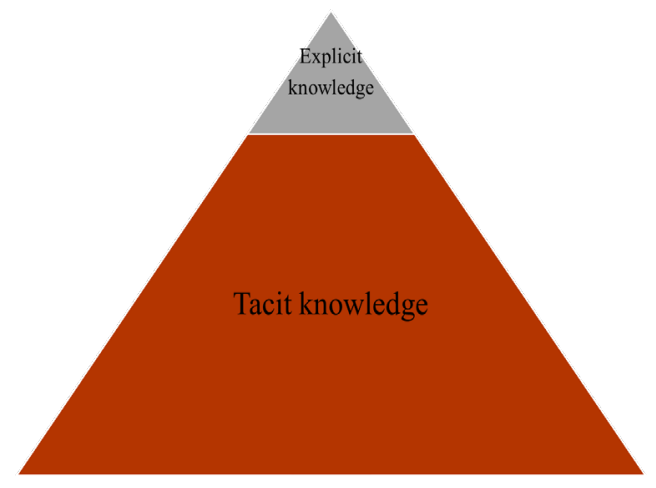

Fig. 3. Types of knowledge within a company [16]

The disproportion of tacit and explicit knowledge is an important aspect to consider as tacit knowledge is comprised of the experience, thinking, competence, commitment, is related to the know-how, know-what, know-why and know-who and is most often known by only a small number of individuals within the company which has the potential of raising problems when and if these individuals decide to stop working within the company [16]. Furthermore, while explicit knowledge is easy to transfer, in the context of tacit knowledge, it has been noted that it is context specific and harder to transfer [13].

It has therefore been the concern of both researchers and professionals throughout the world to find ways of facilitating the transformation of tacit knowledge into explicit knowledge as quickly and optimally possible.

Regarding one of the key components - that of Knowledge Management (KM) and the pivotal role that KM will occupy in the context of Quality 4.0 organizations, it can be noted that KM practices and policies will have to be included as a part of the Organizational culture for Quality 4.0 and furthermore, knowledge will be the enabler for workers to solve complex problems through creativity and innovations [4].

This then raises another concern regarding the implications of integrating Quality 4.0 within an organization which is: How does a company ensure that it gathers the right/relevant data and transfers this data into explicit knowledge as soon as possible? This is the main focus of the paper and the question it tries to provide answers to.

For this, an important delimitation must be made first, that of understanding what sort of tools and techniques will be used by Quality 4.0 organizations, then understanding the skills and abilities required by Quality 4.0, the selection basis for establishing that relevant data is being collected and transformed into tacit knowledge, and last but not least important, understanding the knowledge management process and the most effective way of managing it.

The answer to the first of these aspects has been already covered by Arsovski [2], who in their research presented the proposed Quality 4.0 tools, as shown in Figure 4. 


\begin{tabular}{|c|c|}
\hline Artificial intelligence & $\begin{array}{l}\text { - Computer language processing } \\
\text { - Complex decisions }\end{array}$ \\
\hline Big data & $\begin{array}{l}\text { - Infrastructure for easy access } \\
\text { - Managing and analyzing existing data }\end{array}$ \\
\hline Blockchain & $\begin{array}{l}\text { - Increasing transparency and auditability of transaction } \\
\text { - Monitoring conditions for achieving quality objectives }\end{array}$ \\
\hline Deep learning & $\begin{array}{l}\text { - Image classification, Complex pattern recognition, time services forecasting } \\
\text { - Text generation and recognition, Using heuristics }\end{array}$ \\
\hline Enabling technologies & $\begin{array}{l}\text { - Sensors, } 5 \mathrm{G} \text { networks } \\
\text { - Open-source software }\end{array}$ \\
\hline Machine learning & $\begin{array}{l}\text { - Text analyssis, Fraud detection, Recommendation systems } \\
\text { - Object classification into groups, Forecasting }\end{array}$ \\
\hline Data science & $\begin{array}{l}\text { - Prediction, Simulation, Classification, Inference } \\
\text { - Generating viable models and solutions }\end{array}$ \\
\hline
\end{tabular}

Fig. 4. Quality 4.0 Tools [2]

\section{Conclusions}

The skills and abilities of quality professionals that will lead the transition to Quality 4.0 have been covered by Radziwill [17], who in his paper identified the following five skills as important for quality professionals: 1. system thinking, 2. Data-driven decision-making, 3. Leadership for organizational learning, 4. Establishing processes for continuous improvement, 5. Understanding how decisions affect people's lives, relationships, communities, well-being, health and society in general [17].

As for the means of managing knowledge, a knowledge management approach based on the PDCA cycle that focuses on categorizing the key elements of knowledge management life cycle and integrating these into the PDCA cycle has been used, as presented in Figure 5.
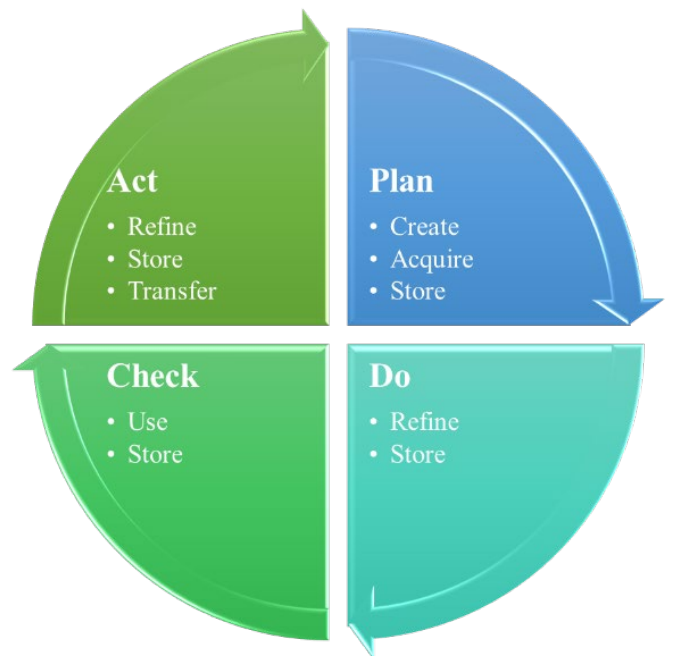

Fig. 5. PDCA based KM life cycle [18]

Based on this information, the author proposed a Knowledge management life cycle for companies that integrate Quality 4.0. The life cycle highlights the tools that could prove to be helpful for the companies for each stage of the PDCA cycle as shown in Figure 6. 


\begin{tabular}{|l|l|}
\hline \multicolumn{1}{|c|}{ Act } & \multicolumn{1}{c|}{ Plan } \\
\cline { 2 - 2 } KM stages & \multicolumn{1}{c|}{ KM stages } \\
Refine|Store|Transfer & Create|Acquire|Store \\
Quality 4.0 tools & Quality 4.0 tools \\
- Enabling technologies & - Artificial intelligence \\
- Data science & - Blockchain \\
& - Enabling technologies \\
\hline Check & \multicolumn{1}{c|}{ Do } \\
\hline \multicolumn{1}{|c|}{ KM stages } & KM stages \\
Use|Store & Refine|Store \\
Quality 4.0 tools & Quality 4.0 tools \\
- Artificial intelligence & - Big data \\
- Machine learning & - Deep learning \\
- Data science & - Machine learning \\
& - Data science \\
\hline
\end{tabular}

Fig. 6. KM life cycle for Quality 4.0

As it can be observed in Figure 6, the "Plan" stage of the proposed model covers three main stages of the knowledge management life cycle: Knowledge creation, Knowledge acquisition and Knowledge storage, and proposes the use of three Quality 4.0 tools: Artificial intelligence, Blockchain and Enabling technologies. In the "Do" stage of the model the Knowledge refining and Knowledge storage stages are covered and four Quality 4.0 tools are being used: Big data, Deep learning, Machine learning and Data science. The "Check" stage of the model focuses on the Knowledge usage and Knowledge storing stages and uses three Quality 4.0 tools: Artificial intelligence, Machine learning and Data science. In the last stage - "Act", the Knowledge refining, Knowledge storing and Knowledge transfer stages are covered and two Quality 4.0 tools are proposed: Enabling technologies and Data science.

Of course, throughout time, as more companies will integrate and reap the benefits of Quality 4.0, more Quality 4.0 tools will emerge and maybe even new quality management tools will be developed in order to better fit the requirements of these companies.

\section{References}

1. A. Chiarini, "Industry 4.0, quality management and TQM world. A systematic literature review and a proposed agenda for further research," The TQM Journal, 32, 4, pp. 603-616, (2020).

2. S. Arsovski, "Social oriented quality: From Quality 4.0 towards Quality 5.0," in 13th IQC Quality Research, Kragujevac, Serbia, (2019).

3. T. Salimova, N. Vatolkina, V. Makolov and N. Anikina, "THE PERSPECTIVE OF QUALITY MANAGEMENT SYSTEM DEVELOPMENT IN THE ERA OF INDUSTRY 4.0," Humanities \& Social Sciences Reviews, 8, 4, pp. 483-495, (2020).

4. M. Sony, J. Antony and J. A. Douglas, "Essential ingredients for the implementation of Quality 4.0," The TQM Journal, 32, 4, pp. 779-793, (2020).

5. J. Nenadál, "The New EFQM Model: What is Really New and Could Be Considered as a Suitable Tool with Respect to Quality 4.0 Concept?" QUALITY INNOVATION PROSPERITY, 24, 1, pp. 17-28, (2020). 
6. Editorial, "Quality management in the 21 st century enterprises: Research pathway towards Industry 4.0," International Journal of Production Economics, 207, pp. 125129, (2019).

7. J. Nenadál, D. Vykydal and E. Tylecková, "Complex Customer Loyalty Measurement at Closed-Loop Quality Management in B2B Area-Czech Example," Sustainability, 13, 5, (2021).

8. A. Calvo-Mora, A. Navarro-García and R. Periañez-Cristobal, "Project to improve knowledge management and key business results through the EFQM excellence model," International Journal of Project Management, 33, 1, pp. 1638-1651, (2015).

9. M. Alavi and D. E. Leidner, "Review: knowledge management and knowledge management systems: conceptual foundations and research issues," MIS Quarterly, 25, 1, pp. 107-136, (2001).

10. T. H. Davenport and L. Prusak, "Working Knowledge-How Organizations Manage What They Know", Boston, MA: Harvard Business School Press, (2000).

11. V. M. Ribière and R. Khorramshahgol, "Integrating Total Quality Management and Knowledge Management," Journal of Management Systems, 16, 1, pp. 39-54, (2004).

12. O. Paulzen, M. Doumi, P. Primoz and A. Cereijo-Roibas, "A Maturity Model for Quality Improvement in Knowledge Management," in ACIS 2002 Proceedings, (2002).

13. K. Linderman, R. G. Schroeder, S. Zaheer, C. Liedtke and A. S. Choo, "Integrating quality management practices with knowledge creation processes," Journal of operations management, 22, pp. 589-607, (2004).

14. L. M. Molina, J. Llorens-Montes and A. Ruiz-Moreno, "Relationship between quality management practices and knowledge transfer," Journal of operations management, 25, pp. 682-701, (2007).

15. D. Fearon, Interviewee, The Smart Factory, Industry 4.0 And Quality. [Interview]. 28 032018.

16. I. L. Magalhães, "Tacit \& Explicit Knowledge," Linkedin, 1312 2015. [Online]. Available: https://www.linkedin.com/pulse/tacit-explicit-knowledge-ivan-luiziomagalh\%C3\%A3es. [Accessed 1004 2021].

17. N. Radziwill, "The Quality 4.0 Revolution: Reveal Hidden Insights Now With Data Science and Machine Learning," in Quality 4.0 Summiton Disruption, Innovation, and Change, Organizational Exellence in Digital Age, Dallas, (2018).

18. R. Dovleac, A. Ionica, M. Leba and A. Rocha, "Knowledge Management Life Cycle Model Based on PDSA for Agile Companies," in Trends and Innovations in Information Systems and Technologies, Budva, (2020). 